\title{
O ESTADO, A EMPRESA E A CIDADANIA COMO AGENTES DE PROTEÇÃO E EFETIVAÇÃO DOS DIREITOS INDIVIDUAIS E TRANSINDIVIDUAIS NA SOCIEDADE DE RISCO.
}

\author{
Jussara Suzi Assis Borges Nasser Ferreira ${ }^{1}$ \\ Ocimar Barros de Oliveira ${ }^{2}$
}

\section{RESUMO}

O presente trabalho tem por objetivo proceder a abordagem acerca das atividades desempenhadas pelo Estado, empresa e cidadania no intuito de conferir maior proteção e efetividade aos direitos fundamentais individuais e transindividuais. Estes atores são protagonistas de ações capazes de influenciar no desenvolvimento sustentável, seja na área econômica, social ou mesmo cultural. A problematização reside na apreensão das consequências da atividade empresarial na sociedade de risco e sua responsabilidade na garantia de um meio ambiente ecologicamente equilibrado, abordando vetores do desenvolvimento e sustentabilidade para as presentes e futuras gerações. O estudo utilizou o método dedutivo e finalístico.

PALAVRAS-CHAVE: Estado; empresa; cidadania; desenvolvimento sustentável; direitos fundamentais.

\section{THE STATE, THE FIRM AND CITIZENSHIP AS AGENTS OF PROTECTION AND EFFECTIVENESS OF INDIVIDUAL AND TRANSINDIVIDUAL RIGHTS IN THE RISK SOCIETY.}

\begin{abstract}
The present work aims to approach the activities carried out by the State, firm and citizenship in order to give greater protection and effectiveness to individual and transindividual fundamental rights. These actors are protagonists of actions capable of influencing the sustainable development, be it in the economic, social or even cultural area. The problematization is the apprehension of the consequences of the business activity in the society of risk and its responsibility in the guarantee of an ecologically balanced environment, addressing vectors of the development and sustainability for the present and future generations. The study used the deductive finalistic method.
\end{abstract}

\footnotetext{
${ }^{1}$ Doutora em direito pela Pontifícia Universidade Católica de São Paulo - PUC; Mestre em Direito pela Universidade Estadual de Londrina. Advogada. Professora permanente do Programa de Doutorado e Mestrado em Direito da Universidade de Marília; Professora permanente do Programa de Mestrado da Universidade Paranaense e professora colaboradora do Programa de Mestrado da Universidade Estadual de Londrina - UEL. Docente da Fundação Escola Superior do Ministério Público de Mato Grosso - FUNESMIP. Coordenadora dos cursos de Pós-Graduação na área de Direito do INBRAPE. Membro efetivo do CONPEDI. Membro efetivo do Instituto Brasileiro de Direito Civil. Endereço Postal: Av. Ayrton Senna da silva, 1055-S1 1202, Ed. Square Garden - Gleba Palhano - Londrina/PR. Email: jussara@bflaw.adv.br.

2 Doutorando em Direito pela Universidade de Marília - UNIMAR; Mestre em Direito Público pela Universidade Federal de Uberlândia - UFU; Especialista em Direito Público pela UFU; Bacharel em Direito e Graduado em Educação Física pela UFU. Professor de Graduação no Centro de Ensino Superior de São GotardoCESG, na UNIPAC de Uberlândia e na FUCAMP de Monte Carmelo; Professor de Especialização na UFU e na FUCAMP de Monte Carmelo. Oficial Registrador do Registro de Títulos e Documentos e Registro Civil de Pessoas Jurídicas da Comarca de Rio Paranaíba-MG. Endereço postal: Rua Capitão Franklin de Castro, 994, Centro, Rio Paranaíba-MG. Email: aspex37@ yahoo.com.br.
} 
KEYWORDS: State; firm; citizenship; sustainable development; fundamental rights.

\section{INTRODUÇÃO}

A contemporaneidade, com o advento da quarta Revolução Industrial, passa por profundas transformações nas mais variadas áreas, a saber, tecnologia, meio ambiente, relações sociais, economia e relações internacionais.

O presente trabalho tem por objetivo proceder à abordagem acerca das atividades desempenhadas pelo Estado, empresa e cidadania no intuito de conferir maior proteção e efetividade aos direitos fundamentais individuais e transindividuais.

Vive-se em um mundo mais tecnológico, mais conectado e mais globalizado. Neste contexto o Estado, a empresa e a cidadania ${ }^{3}$ precisam se reinventar, mesmo porque as relações jurídicas da individualidade estão sendo suplantadas pelas relações jurídicas da transindividualidade. Ações praticadas no ambiente social são capazes de surtir efeitos locais, regionais, globais e, porque não dizer, intertemporais. Basta lembrar que o art. 225 da Constituição da República Federativa do Brasil menciona o direito ao meio ambiente equilibrado para presentes e futuras gerações. O processo civil desloca-se do eixo do individualismo para as ações coletivas, abarcando direitos difusos, coletivos e individuais homogêneos.

O Estado contemporâneo tem que se moldar a este novo contexto, já que no cenário internacional não há mais como sustentar a ideia, propalada na Idade Moderna, de soberania como poder que não admite nenhum poder acima do seu. Essa teoria foi estopim de guerras e afrontas à dignidade da pessoa humana. Hodiernamente existem organizações internacionais, a exemplo da Organização das Nações Unidas - ONU, que impõem sua vontade até mesmo ao soberano Estado, dando novos contornos ao conceito de soberania.

Neste cenário está inserida a empresa, como instituição que se apodera dos meios de produção no intuito de disponibilizar no mercado produtos e serviços que atendam as demandas dos consumidores e assim atinja seu objetivo primevo, que é a obtenção de lucros. Embora pareça clara e simplista esta definição, a empresa está inserida neste complexo de

\footnotetext{
${ }^{3}$ A concepção mais moderna de cidadania radica o cidadão a uma coletividade na qual possa exercer seus direitos de cidadania e, ainda, utilizar de instrumentos que garantam desde os mais elementares direitos da cidadania, podendo citar como exemplo a cidadania uberlandense, mineira, brasileira, francesa, etc. (Oliveira, Ocimar Barros de. Revista Jurídica Direito e Realidade, Monte Carmelo-MG, V.01, n.01, Jan./Jun. 2011, p.196 ISSN 2236-0492)
} 
relações estatais, sociais e ambientais. Não dá para dissociar a atividade empresarial de suas consequências sociais, culturais e ambientais. A atividade empresarial está inserida numa sociedade de risco e é um dos agentes responsáveis pelo desenvolvimento econômico e social sustentável, sem olvidar a preservação do meio ambiente, já que muitas atividades empresariais são capazes de degradar grandes áreas, como o exemplo da mineração e do desmatamento para diversos fins.

De outro polo, tem-se a cidadania que desempenha papel não menos importante que os do Estado e da empresa, aqui entendida como coletivo de cidadãos, mesmo porque engloba grupos locais, regionais e porque não mencionar a cidadania global, que se preocupa com problemas mundiais, como a preservação da paz, do meio ambiente, a distribuição de renda e o combate à fome, à miséria e à violência.

A participação do cidadão demanda educação para a cidadania. Desenvolvimento com liberdade envolve acesso à informação e ao conhecimento, efetivação dos direitos e garantias fundamentais que são capazes de conferir ao cidadão uma vida mais digna e mais participativa nas políticas públicas e sociais.

Enfatiza-se a importância da liberdade como fator de desenvolvimento nos moldes propostos por Amartya Sen, no sentido de liberdade e oportunidade para participar da discussão pública e da interação social, por ter papel construtivo na formação de valores e éticas.

Neste viés que está assentada a problematização da investigação almejando respostas para os papéis do Estado, da empresa e da cidadania, neste contexto mais tecnológico, produtivo, globalizado, que, todavia, ainda não foi capaz de solucionar problemas cruciais, como o desenvolvimento social, a distribuição de renda, o desenvolvimento sustentável, a liberdade com o acesso à informação e ao conhecimento, especialmente nos países subdesenvolvidos e em desenvolvimento.

O estudo se desenvolve à luz da Análise Econômica do Direito, que é um movimento interdisciplinar que lança sobre o direito influências da ciência social econômica, propondo uma nova leitura do direito à luz da economia. Foram ainda empregados os métodos dedutivo e finalístico.

Nesse entendimento, não há como dissociar atuação estatal, empresarial e cidadã do objetivo que é o desenvolvimento sustentável em todas as suas vertentes: jurídica, econômica, social, cultural e ambiental. 


\section{DESLOCAMENTO DA PROCESSUALIDADE INDIVIDUAL PARA A TRANSINDIVIDUAL:}

O Código Civil Brasileiro de 1916, influenciado pela teoria liberal europeia e norte americana, foi um verdadeiro tratado da propriedade privada. O Código de Processo Civil que o instrumentalizava previa um processo individualista, no qual caberia ao Estado juiz julgar casos do indivíduo "A" contra o indivíduo "B". Quando muito, o Código de Processo Civil pátrio previa a formação de litisconsórcios para solucionar litígios envolvendo um grupo de pessoas com mesmo pedido e causa de pedir.

O Código Civil de 1916 tornou-se obsoleto e ineficaz para acompanhar as evoluções da sociedade brasileira. Ocorreu o fenômeno que foi denominado de publicização/constitucionalização do Direito privado, que é na verdade uma socialização universal das relações jurídicas, ou seja, do Direito como um todo. A esse respeito assim se posiciona Reale: “se não houve a vitória do socialismo, houve o triunfo da 'socialidade', fazendo prevalecer os valores coletivos sobre os individuais, sem perda, porém, do valor fundante da pessoa humana" (1998, p. 23)

Seguindo a esteira das mudanças ocorridas nos meios social e econômico, foi editado o Código Civil de 2002, que traz logo no primeiro livro da parte especial o direito das obrigações e, em seguida, no segundo livro, o direito de empresa que é uma inovação no presente código, para somente depois tratar de direito das coisas, família e sucessão, rompendo com a estrutura do Código Civil de 1916.

Percebe-se que a sociedade mundial passa por notáveis transformações e estas redundaram em uma nova abordagem do Direito Civil e de outros ramos do Direito. Afinal, qualquer manual de introdução ao estudo do direito menciona que o Direito evolui em função da sociedade.

A esse respeito, as precisas palavras de Fachin:

Para captar transformações pelas quais perpassa o Direito Civil contemporâneo, há lugar para uma nova introdução que se proponha a reconhecer a travessia em curso e que se destine a um olhar diferenciado sobre as matérias que compõem o objeto de análise. Clara premissa que instiga a possibilidade de reconhecer que o reinado secular de dogmas, que engrossam as páginas de manuais e que engessaram parcela significativa do Direito Civil começa a ruir. Trata-se de captar os sons dessa primavera em curso, com os efeitos da nova codificação civil. (FACHIN, 2003, p. 01). 
A sociedade intensificou as relações sociais e comerciais, o que redundou no consumismo de massa e, com isso, surgiram novas demandas que não ficaram afetas apenas ao âmbito do indivíduo, perpassando para interesses e direitos da coletividade.

Sinara Lacerda Andrade assim contextualiza:

Com a globalização, a abertura do comércio internacional, a circulação de bens e serviços entre as nações, a possibilidade de escoamento de produção e a inserção das novas tecnologias propiciaram, neste contexto social, uma aproximação entre as nações, visto que a rede mundial de computadores oportunizou e facilitou o consumismo. (ANDRADE, 2017, p. 15)

Hodiernamente, as relações jurídicas e processuais sofreram uma transmutação. Os tribunais abarrotados, e muitas vezes emperrados, não são capazes de lidar com o grande número de demandas repetitivas, nas quais tenham que julgar caso a caso.

Por isso, o novel Código de Processo Civil Brasileiro de 2015 vem trazendo institutos que podem auxiliar no desafogamento das varas e tribunais, em especial aqueles previstos no art. 927 do $\mathrm{CPC}$, que assim normatiza: “Art. 927. Os juízes e tribunais observarão: I - as decisões do Supremo Tribunal Federal em controle concentrado de constitucionalidade; II - os enunciados de súmula vinculante; III - os acórdãos em incidente de assunção de competência ou de resolução de demandas repetitivas e em julgamento de recursos extraordinário e especial repetitivos; IV - os enunciados das súmulas do Supremo Tribunal Federal em matéria constitucional e do Superior Tribunal de Justiça em matéria infraconstitucional; V - a orientação do plenário ou do órgão especial aos quais estiverem vinculados".

Os processualistas pátrios denominam de precedentes vinculantes a previsão do artigo 927 do CPC, sendo notório que o julgamento com base em precedentes vinculantes não está arraigado à cultura processual brasileira, já que advém de uma matriz de common law e o Brasil adota o civil law. Por esse motivo, autores, como Lenio Luiz Streck, denominam-os de precedentes à brasileira e assevera Streck: "Em suma, é algo assim: o precedente vincula porque assim decidiu um órgão dotado de autoridade”. (2016, p. 401).

Os tribunais e juízes terão que se adequar a essa nova prática, que numa análise econômica do direito pode surtir efeitos positivos no sentido de reduzir a morosidade do judiciário e propiciar a otimização no emprego de recursos humanos, materiais e financeiros.

Por outro lado, mas de relevante importância e um dos focos centrais da presente investigação, tem-se os direitos transindividuais, consubstanciados nos direitos difusos, coletivos e individuais homogêneos. Tais direitos são passíveis de processos cujas decisões 
produzem efeitos que se destinam a grupos definíveis ou mesmo indefiníveis de pessoas.

Gregório Assagra de Almeida, com muita propriedade, assim se posiciona sobre os direitos transindividuais:

Transindividualidade, supra-individualidade, metaindividualidade são conceitos que, no campo do direito, especialmente no aspecto da dimensão subjetiva da titularidade, se sobrepõem ao indivíduo para abranger uma comunidade ou uma coletividade de pessoas geralmente indetermináveis ou indeterminadas. A transindividualidade é uma característica própria dos denominados "direitos de terceira dimensão". Foi a partir da terceira dimensão dos direitos que se começou a construir uma nova teoria para os direitos, uma teoria dos direitos de dimensão coletiva, uma teoria da transindividualidade subjetiva (titularidade) e objetiva (objeto) dos nossos direitos das massas. (2008, p. 473)

A definição de direitos difusos, coletivos e individuais homogêneos no direito brasileiro coube primeiramente ao Código de Defesa do Consumidor, no parágrafo único do art. 81 que assim define: "Parágrafo único. A defesa coletiva será exercida quando se tratar de: I - interesses ou direitos difusos, assim entendidos, para efeitos deste código, os transindividuais, de natureza indivisível, de que sejam titulares pessoas indeterminadas e ligadas por circunstâncias de fato; II - interesses ou direitos coletivos, assim entendidos, para efeitos deste código, os transindividuais, de natureza indivisível de que seja titular grupo, categoria ou classe de pessoas ligadas entre si ou com a parte contrária por uma relação jurídica base; III - interesses ou direitos individuais homogêneos, assim entendidos os decorrentes de origem comum.

$\mathrm{O}$ art. 82 do CDC se encarrega de delimitar a legitimidade ativa para os interesses transindividuais: I - O Ministério Público; II - a União, os Estados, os Municípios e o Distrito Federal; III - as entidades e órgãos da administração Pública, direta ou indireta, ainda que sem personalidade jurídica, especificamente destinados à defesa dos interesses e direitos protegidos pelo CDC; IV - as associações legalmente constituídas há pelo menos um ano e que incluam entre seus fins institucionais a defesa dos interesses e direitos protegidos por este código, dispensada a autorização assemblear.

Dada a importância e amplitude da conceituação traçada pelo parágrafo único do art. 81 do CDC no que tange aos direitos e interesses transindividuais, entende-se que seja norma que surte seus efeitos para além do CDC, ou seja, norma de ultraeficácia, assim se posicionando Gregório Assagra de Almeida:

Portanto, o art. 81, parágrafo único do CDC constitui-se em norma jurídica de ultraeficácia, de eficácia potencializada. Seria norma de superdireito material coletivo. Definições em sentido contrário não têm aplicabilidade aos casos concretos conduzidos à apreciação jurisdicional. (2008, p. 475) 
Percebe-se que com a demarcação de tais definições instala-se novo paradigma na processualidade brasileira, deslocando-se o eixo da processualidade das decisões unicamente individuais ou litisconsorciais para uma processualidade coletiva, na defesa de interesses ou direitos coletivos, difusos ou individuais homogêneos.

\section{O PAPEL DO ESTADO NA SOCIEDADE MASSIFICADA.}

Neste cenário, tem-se o Estado como pessoa jurídica de direito público. Muitas são as teorias que discutem a origem da sociedade e do Estado, a correlação entre Estado e direito e, até mesmo, se há uma real necessidade da instituição Estado para regular a vida em sociedade.

Diante da incontestável existência e personalidade jurídica do Estado, mister se faz a modernização e readequação das funções estatais diante das evoluções ocorridas no seio da sociedade, para que aquele possa concretizar sua atuação em prol de uma sociedade que tem mais acesso à informação, às liberdades e à participação democrática. Amartya Sen ao abordar os valores éticos e a elaboração de políticas públicas, assim se posiciona:

Para a elaboração das políticas públicas é importante não apenas avaliar as exigências de justiça e o alcance dos valores ao se escolherem os objetivos e as prioridades da política pública, mas também compreender os valores do público em geral, incluindo o seu senso de justiça. (2016, p. 349)

Importante descortinar os perfis que o Estado vem assumindo, desde a concepção do Estado Liberal burguês até o presente Estado pós-moderno, neoliberal e cujas relações jurídicas fazem emergir um direito material e processual transindividual. O Estado tem papel relevante na efetivação dos direitos fundamentais e deve demarcar sua atuação de forma a conferir-lhes eficácia e, em especial, às conquistas das três primeiras dimensões, que envolvem liberdade, igualdade e fraternidade, pois da consolidação destas três dimensões decorrem as demais.

Acerca das dimensões dos direitos fundamentais, importante salientar que os direitos de primeira dimensão são os individuais da pessoa humana em face do Estado e se caracterizam por uma prestação negativa, obrigação de não fazer do Estado. São direito civis e políticos: vida, liberdade, segurança, propriedade. Visam proteger o cidadão contra arbitrariedades passíveis de serem cometidas pelo Estado.

A segunda dimensão cuida dos direitos sociais, culturais e econômicos. Direitos estes que buscam a igualdade. O Estado é compelido a uma prestação positiva, ou seja, obrigação 
de fazer, com o intuito de conferir aos menos privilegiados acesso aos bens da vida, capazes de conferir maior dignidade à pessoa humana e, assim, reduzir as desigualdades sociais.

A terceira dimensão reúne os direitos de fraternidade e solidariedade, cabendo ao Estado velar pela coletividade e até mesmo pelos direitos e interesses de gerações futuras. A terceira dimensão abarca os direitos da criança e do adolescente, do idoso, a defesa do consumidor, do meio ambiente, paz e autodeterminação dos povos, dentre outros.

A quarta dimensão, na visão de Norberto Bobbio (1992, p. 14) está afeta à defesa do patrimônio genético, envolve a ética, a pesquisa científica e biológica. Para Paulo Bonavides (2008, p. 572) a quarta dimensão compreende a cidadania e a liberdade de todos os povos.

Paulo Bonavides propõe ainda uma quinta dimensão dos direitos fundamentais, na qual destaca o direito à paz:

Estuário de aspirações coletivas de muitos séculos, a paz é o corolário de todas as
justificações em que a razão humana, sob o pálio da lei e da justiça, fundamenta o
ato de reger a sociedade, de modo a punir o terrorista, julgar o criminoso de guerra,
encarcerar o torturador, manter invioláveis as bases do pacto social, estabelecer e
conservar intangíveis as regras, princípios e cláusulas da comunhão política. (2009,
p.590)

Bonavides define contornos do direito à paz como um direito natural dos povos, ou seja, como um direito constitucional do gênero humano, na perspectiva da paz perpétua propalada pelo modelo de Kant, sendo que aquele que a violar estará cometendo crime contra a sociedade humana.

E com brilhantismo, contextualiza Bonavides:

No mundo globalizado da unipolaridade, das economias desnacionalizadas, das soberanias relativizadas e dos poderes constitucionais desrespeitados, ou ficamos com a força do direito ou com o direito da força. Não há mais alternativa. A primeira nos liberta, a segunda nos escraviza. (2009, p. 592)

O Estado contemporâneo deve se reinventar para cumprir sua missão de Estado Democrático e Social de Direito, fortalecendo a democracia e a participação da cidadania, e cumprindo a constituição para conferir eficácia aos direitos fundamentais, valorização do trabalho, da livre iniciativa e combate à miséria.

Para melhor entendimento do papel do Estado na sociedade contemporânea, importante realizar breve bosquejo sobre os modelos de Estado adotados desde o Liberalismo burguês até o Neoliberalismo contemporâneo. Observa-se que no Estado Liberal burguês que se implantou no período pós-revoluções burguesas, em especial a Revolução Francesa de 1789 - firmada como marco inicial da Idade Contemporânea - é o Estado que dá grande 
enfoque aos direitos fundamentais de primeira dimensão, pautado nas liberdades civis e políticas e não intervenção do Estado nas relações privadas.

Na segunda metade do século XVIII, surgiu na França a escola liberal, conhecida também como escola individualista, a qual pregava que toda atividade econômica deve ter por fim a felicidade dos indivíduos, afirmando também que toda atividade econômica deve ser exercida pelos indivíduos, sendo o papel do Estado reduzido ao mínimo possível. Faziam parte desta escola grandes economistas, tais como, Adam Smith, Malthus, Ricardo, Stuart Mill e J. B. Say.

Sob a égide do Estado Liberal burguês, houve um momento histórico de exploração da classe trabalhadora pela burguesia, detentora dos meios de produção. Tal fato provocou um grande distanciamento entre as classes sociais. O Estado não poderia mais manter sua passiva posição de Estado não interventor. A classe trabalhadora clamava por direitos sociais afetos à segunda dimensão dos direitos fundamentais.

Oportuno explicitar, nas palavras de Caio Tácito, as principais causas para a crise do Estado Liberal:

a) o reconhecimento de que determinadas atividades econômicas estão imbuídas, por sua natureza, de um interesse coletivo, afetando, praticamente, em sua exploração, a generalidade do grupo social; b) a exploração capitalista de atividades privadas e a competição predatória entre grupos se extrema em abusos lesivos a interesses indefesos e sem a representação eficaz, sensibilizando a opinião pública e inspirando o legislador, o juiz e o administrador na proteção ao economicamente fraco. $\mathrm{O}$ aviltamento da mão-de-obra lança as sementes da proteção ao trabalhador e da representação sindical. A política de preços espoliativos, as manipulações da produção e do comércio, as concentrações de capital visando lucros imoderados ou monopólios de mercado contrastam com os interesses do público consumidor, conduzindo ao regime de controle de tarifas e preços, a defesa da economia popular e às medidas contra as concentrações de capital; c) a expansão dos grupos capitalistas entra em conflito com os próprios órgãos do poder político, sobre os quais atua, cuidando de aperfeiçoá-los aos seus interesses econômicos (o poder dentro do poder). (1997, p. 378)

No início do século XX, com os adventos da Constituição do México de 1917 e da Constituição Alemã de 1919 (Constituição de Weimar), houve a inserção de direitos sociais nos referidos textos constitucionais. Citadas constituições influenciaram os demais países que passaram a inserir um rol de direitos sociais em suas cartas constitucionais. O Estado sai então de sua postura liberal e inaugura o Estado do Bem Estar Social (Welfare State), com vista a conferir direitos sociais aos menos privilegiados, diga-se, à classe trabalhadora e, assim, reduzir as desigualdades sociais. 
A postura de Estado assistencialista e interventor, embora importante em determinado momento da história, redundou ao Estado o inchaço da Administração Pública que abraçou muitas funções assistencialistas, previdenciárias, protecionistas e sociais. Tal papel, assumido pelo Estado, diante da necessidade de intervenção, ganhou força e se potencializou com o advento da Grande Depressão de 1929 e seus reflexos na década de trinta. Em decorrência da crise de 1929, economistas, dentre eles se destacando John Maynard Keynes (1883/1946), vieram a contestar as teorias de Adam Smith.

Lima assim se posiciona sobre o pensamento Keynesiano:

Para Keynes, o regime do laissez-faire, com cada um buscando atingir seus objetivos
individuais, não conseguiria atender aos interesses coletivos. Por essa razão,
defendia uma ação inteligente do Estado na condução econômica do país em
convivência com a livre iniciativa privada. Em sua visão, o bem-estar e o progresso
econômico só seriam alcançados se o capitalismo fosse dirigido inteligentemente e
se o poder estatal ocupasse o lugar de regulador, não podando iniciativas
individuais. (1999, p. 32)

Ao assumir tais funções, o Estado, além de se tornar burocrático, passa a ter dificuldades em manter serviços de qualidade e a preços módicos, já que o mundo se torna mais populoso e as demandas por serviços públicos e assistenciais aumentam consideravelmente. O Estado passa, então, após a Segunda Guerra Mundial, e com ênfase na segunda metade do século XX, a fazer um movimento inverso, no sentido de privatização de serviços públicos e reforma de serviços previdenciários e assistenciais. A esta nova fase do Estado os doutrinadores intitulam de Estado Neoliberal que, em suma, representa uma corrente política e teórica que se contrapõe ao Estado intervencionista.

Um dos grandes expoentes da teoria neoliberalista foi Milton Friedman (1912-2006), matemático economista que nasceu no Brooklyn e morreu em São Francisco. Friedman se projetou por meio do livro Capitalismo e liberdade que expunha suas ideias neoliberais. Com a publicação do livro, ganhou o prêmio Nobel em 1976. Juntamente com ele, grandes pensadores como Karl Popper, Lionel Robbins, Ludwing Von Mises, Walter Eupken, Walter Lipman, Michael Polanyi, Salvador de Madariaga constituíram a Sociedade de Mont Pèlerin, na Suíça, que parecia uma franco-maçonaria neoliberal, cuja finalidade era combater o Estado intervencionista. (LIMA, 1999, p. 09-10)

O Estado Neoliberal teve a mais expressiva implantação com as ações de Margareth Thatcher na Inglaterra e de Ronald Reagan nos Estados Unidos, ações ocorridas nas décadas de 1970 e 1980. 
O neoliberalismo parte da ideologia de que o mercado é quem regula a vida social e defende os direitos da propriedade privada, afirma que ao Estado estariam afetas as funções mínimas de defesa nacional e manutenção da ordem neoliberal.

O ingresso do neoliberalismo no Brasil é atribuído ao governo do Presidente Fernando Collor, na década de 1990, e sua continuidade ocorreu com o Presidente Fernando Henrique Cardoso.

Esse é, por fim, o cenário que se descortina, inserindo o Estado no contexto de uma sociedade massificada e de risco, na qual deve dispensar especial atenção aos direitos fundamentais, dando ênfase aos de terceira dimensão por se tratarem de direitos e interesses que perpassam o individualismo e têm como titulares uma coletividade definível ou indefinida.

Após essa breve evolução histórica e teórica sobre os modelos de Estado, convém demarcar que o Estado brasileiro está sob a égide da Constituição Federal de 1988, tida como democrática, mas que também é conhecida como uma constituição social e econômica, já que destina seu capítulo II, a partir do art. $6^{\circ}$, aos direitos sociais e se preocupa em constitucionalizar a ordem econômica e financeira em seu título VII, capítulo I, que trata dos princípios da atividade econômica. $\mathrm{O}$ art. 170 da CF/88 dispõe que "a ordem econômica, fundada na valorização do trabalho humano e na livre iniciativa, tem por fim assegurar a todos existência digna, conforme ditames da justiça social, observados os seguintes princípios: I- soberania nacional; II - propriedade privada; III - função social da propriedade; IV - livre concorrência; V - defesa do consumidor; VI - defesa do meio ambiente, inclusive mediante tratamento diferenciado conforme o impacto ambiental dos produtos e serviços e de seus processos de elaboração e prestação; VII - redução das desigualdades regionais e sociais; VIII - busca do pleno emprego; IX - tratamento favorecido para as empresas de pequeno porte constituídas sob as leis brasileiras e que tenham sua sede e administração no País." O parágrafo único do artigo sob comento dispõe: "É assegurado a todos o livre exercício de qualquer atividade econômica, independentemente de autorização de órgãos públicos, salvo nos casos previstos em lei."

O atual Estado Neoliberal e pós-moderno precisa se adequar para, através de sua atuação, conferir maior eficácia e efetividade ao rol de direitos fundamentais, individuais e transindividuais, buscando encontrar o ponto de equilíbrio entre os interesses sociais e 
mercadológicos e, também, entre a regulação da atividade econômica e o não intervencionismo exacerbado.

\section{O PAPEL DA EMPRESA NA CONSOLIDAÇÃO DOS DIREITOS FUNDAMENTAIS EM UMA SOCIEDADE DE RISCO.}

A empresa tem relevante papel na atual sociedade de risco, mesmo porque é uma das molas mestras do desenvolvimento nos Estados que adotam o sistema capitalista. Contudo, tem a difícil missão de aliar à busca do lucro sua função social, ou seja, valores como desenvolvimento social e econômico sustentáveis, preservação do meio ambiente, práticas de mercado que atendam à boa fé objetiva dos contratos e combate à corrupção nos seus mais variados desdobramentos.

Acerca da boa fé objetiva nos contratos, assim se posicionam Ferreira e Almeida:

O dever de agir de acordo com a boa-fé está presente em todas as fases da vida do contrato. Manifesta-se, pois, nas negociações que precedem o contrato, resultando da sua violação a responsabilidade pré-contratual, na execução do contrato e, inclusive, após a extinção do mesmo, representado pelo momento pós-eficacial do contrato cumprido. (2003, p. 40)

Outro problema a ser combatido, não somente pelas empresas como pelo Estado e sociedade civil organizada, é a persistente prática da corrupção, que, cabe pontuar, não é problema recente; porém, capaz de prejudicar sobremaneira o desenvolvimento econômico, social e as políticas públicas e ainda servir como estímulo a atividades ilícitas. Nesse sentido, assim se posiciona Amartya Sen:

A prevalência da corrupção é justificadamente considerada uma das piores barreiras no caminho do progresso econômico bem-sucedido - como, por exemplo, em muitos países asiáticos e africanos. Um nível elevado de corrupção pode tornar ineficazes as políticas públicas e também afastar o investimento e as atividades econômicas de setores produtivos, direcionando-os às colossais recompensas das atividades ilícitas. (2010, p. 350)

A importância da função social da empresa é mencionada pela Lei de Recuperação de Empresas e Falência, Lei 11.101/2005, em seu artigo 47 dispõe que a recuperação judicial tem por objetivo viabilizar a superação da situação de crise-econômico-financeira do devedor, a fim de permitir a manutenção da fonte produtora, do emprego dos trabalhadores e dos interesses dos credores, promovendo, assim, a preservação da empresa, sua função social e o estímulo à atividade econômica.

Do artigo supra, depreende-se que as empresas têm papel relevante para o desenvolvimento econômico e social e, muitas vezes, sua preservação, por meio de uma 
recuperação judicial que mantenha as expectativas de recebimento dos créditos por parte dos empregados e credores, somadas à preservação de vagas de emprego para a população, é muito mais importante econômica e socialmente do que a decretação de sua falência.

No entanto, como dito alhures, a empresa tem que se reinventar e encontrar seu lugar e papel dentro de uma sociedade mais tecnológica, mais informada e ainda mais exigente.

Makaay e Rousseau enfatizam que, além dos custos sociais, a decisão de empreender envolve custos de transação que devem ser levados em conta numa análise econômica da empresa e do direito, e assim se posicionam:

A contribuição de Coase, nesse aspecto é acentuar que o processo de troca é complexo, uma vez que o mercado oferece preços conhecidos que guiam o empresário nas suas operações. A contribuição de Coase, nesse aspecto, é que o processo de troca é complexo e gera custos, denominados custos de transação, que devem ser considerados pelo empresário na sua decisão de organizar as atividades de produção. (2015, tópico 1704).

O Estado e a sociedade (cidadania) têm sido exigentes no que tange à análise dos impactos ambientais, econômicos e sociais de implantação de atividades potencialmente agressivas ao meio ambiente, que desrespeitem os direitos trabalhistas e humanos, numa verdadeira análise de custos e benefícios, a qual perpassa pela análise econômica do Direito.

Empresas que não cuidam de sua imagem social e desrespeitam as leis de mercado, os direitos humanos e ambientais estão sujeitas até mesmo a boicotes por parte dos consumidores mais informados, que não coadunam com tais práticas, além das penalidades impostas pela regulação estatal. Ocorreram recentemente boicotes a marcas que utilizam de mão-de-obra de trabalhadores em situação análoga à de escravo. Marcas famosas tiveram suas imagens difamadas e o consumo de seus produtos reduzidos, por se beneficiarem de tais práticas.

Ademais, as atividades empresariais terão que passar pelo crivo do Estado e da cidadania, no que tange ao licenciamento de atividades potencialmente nocivas ao meio ambiente, donde se depreende a importância dos papéis dos três agentes envolvidos: Estado, empresa e cidadania. Neste sentido, versa o artigo $3^{\text {o }}$ da Resolução 237/1997 do Conselho Nacional do Meio Ambiente - CONAMA:

Art. $3^{\circ}$ - A licença ambiental para empreendimentos e atividades consideradas efetiva ou potencialmente causadoras de significativa degradação do meio dependerá de prévio estudo de impacto ambiental e respectivo relatório de impacto sobre o meio ambiente (EIA/RIMA), ao qual dar-se-á publicidade, garantida a realização de audiências públicas, quando couber, de acordo com a regulamentação.

Percebe-se que, não obstante a atividade empresarial seja capaz de gerar riqueza, empregos e desenvolvimento, há que se aquilatar o custo ambiental de tal atividade, ou seja, 
se é considerada efetiva ou potencialmente causadora de significativa degradação ao meio ambiente, numa verdadeira ponderação de custo e benefício. Deste processo, participam a empresa proponente da atividade, o Estado com a devida regulação e processo administrativo de licenciamento e a cidadania, por meio da participação em audiências públicas quando exigidas por lei, ou mesmo utilizando outros instrumentos de participação popular, como passeatas, protestos, direito de petição, ação popular etc.

Desse modo, percebe-se que a empresa, na atual sociedade capitalista, pós-moderna e neoliberal, ainda que revestida de seu principal objetivo que é a obtenção de lucro, não pode se descuidar das exigências impostas pela regulação estatal, pelas relações trabalhistas e de consumo, no sentido de cumprir sua função social.

Não se pode olvidar que o mercado, globalizado e influenciado pelas sucessivas crises econômicas ocorridas ao longo da história, tem se tornado mais exigente no que diz respeito a relações mais transparentes, honestas e que dão ênfase ao combate à corrupção pública e privada. Tudo num esforço para conferir mais estabilidade ao mercado e, com isso, maior credibilidade às empresas, sobretudo às grandes corporações que extrapolam os limites nacionais e atuam no mercado internacional, além de disponibilizarem ações nas principais bolsas de valores e, desta forma, captarem recursos da poupança privada.

A empresa, seja grande, média ou pequena, convive com o paradigma contemporâneo de otimizar os meios de produção e as relações mercadológicas e de consumo sem perder de vista sua função social como geradora de empregos, como instrumento de desenvolvimento econômico e social, bem como o apelo da preservação do meio ambiente para as presentes e futuras gerações.

\section{O PAPEL DA CIDADANIA NA CONSOLIDAÇÃO DOS DIREITOS FUNDAMENTAIS NA ATUAL SOCIEDADE DE RISCO.}

Os cidadãos também desempenham papel primordial na consolidação dos direitos fundamentais previstos na Constituição Federal de 1988 e demais diplomas nacionais e internacionais de direitos humanos.

A República Federativa do Brasil, conforme dispõe o preâmbulo da Carta Magna, foi instituída como:

Estado Democrático, destinado a assegurar o exercício dos direitos sociais e individuais, a liberdade, a segurança, o bem-estar, o desenvolvimento, a igualdade e 
a justiça, como valores supremos de uma sociedade fraterna, pluralista e sem preconceitos, fundada na harmonia social e comprometida, na ordem interna e internacional, com a solução pacífica das controvérsias.

Como consectário, o parágrafo único do artigo $1^{\circ}$ vem enfatizar a titularidade do poder a ser exercida pelo povo. ${ }^{4}$ Se todo poder emana do povo, não há como negar a imprescindibilidade da participação da cidadania na construção de uma ordem econômica e social baseada nos princípios reitores dos direitos humanos e econômicos. E assim se consolida a tríade proposta para a construção deste edifício jurídico e econômico, cujos obreiros são o Estado, a empresa e a cidadania. Neste sentido o posicionamento de Dowbor aponta que:

De forma geral, buscamos hoje articular o Estado, o mundo empresarial e a sociedade civil, visando um desenvolvimento que seja socialmente justo, economicamente viável, e sustentável em termos ambientais. Nesta visão de articulações sociais, não podemos esquecer que a sociedade civil constitui o objetivo final das nossas atividades: quem terá, ou deixará de ter, qualidade de vida, é a sociedade, e as pessoas físicas que a constituem, e não o "Estado" ou uma pessoa jurídica como a "empresa". O Estado e a empresa, por importantes que sejam, constituem meios. Inclusive, é da participação informada da sociedade que depende em grande parte o bom funcionamento tanto do Estado como das empresas. (2004, p. 08)

Uma sociedade civil organizada e bem informada é fator preponderante para o desenvolvimento sustentável em todas as suas vertentes: social, econômica, cultural e ambiental.

Deve-se levar ainda em consideração que o Estado costuma desempenhar mais de um papel, ora como Estado regulador das atividades econômicas e sociais, ora como Estado fornecedor de produtos e serviços tais como: educação, transporte, saúde, água potável, energia, combustíveis etc.

Considerando que o Brasil é uma democracia relativamente recente, com a promulgação da Constituição Cidadã em 1988, deve-se ressaltar a importância de uma democracia participativa, que insira a cidadania na arena de discussão dos principais problemas políticos, sociais e econômicos que a nação enfrenta.

Descortina-se a importância do exercício da cidadania, embora a sociedade brasileira necessite construir uma cultura de participação, em função de possuir uma perceptível apatia para a discussão de políticas públicas, herança de décadas de governos ditatoriais e opressores.

\footnotetext{
${ }^{4}$ Art. 1ํ, parágrafo único da CF/88: Todo poder emana do povo, que o exerce por meio de representantes eleitos ou diretamente, nos termos desta Constituição.
} 
Faz-se necessário, ainda, uma educação voltada para o exercício da cidadania, dentro de uma perspectiva efetiva, haja vista que a mera previsão no campo formal não é suficiente para que ocorra uma verdadeira participação.

O artigo 205 da Constituição Federal preconiza que a educação visa ao pleno desenvolvimento da pessoa, seu preparo para o exercício da cidadania e sua qualificação para o trabalho. 5

A participação da cidadania na construção de uma verdadeira democracia é tão importante que alguns doutrinadores têm apresentado propostas no sentido que seja guindada ao status de sexta dimensão dos direitos fundamentais, vê-se que estes correspondem à democracia, à liberdade de expressão, ao direito de informação e ao pluralismo político. ${ }^{6}$

Numa sociedade polarizada entre fornecedores e consumidores, consubstanciando uma sociedade de consumo e de risco, a participação do cidadão representa mais que a esporádica participação em eventos de políticas públicas. Para a consolidação de uma democracia mais participativa, deve a cidadania se empoderar, utilizando de todos os instrumentos que estiverem à sua disposição para reivindicar, protestar, reclamar, requerer, ter acesso à informação, manifestar sua opinião nos mais diversos temas e segmentos.

\section{CONCLUSÃO}

O mundo contemporâneo passa por profundas transformações, sendo cada vez mais tecnológico, globalizado e conectado (interligado). Neste contexto, convivem os três principais atores das relações jurídicas, econômicas e sociais, a saber: o Estado, a empresa e a cidadania.

O direito civil e respectivo processo passam por um deslocamento do eixo das relações individuais para as relações transindividuais, assim entendidos os direitos difusos, coletivos e individuais homogêneos. Essa tendência é denominada de publicização ou constitucionalização do direito civil.

Estado, empresa e cidadania têm papéis relevantes na proteção e na consolidação dos direitos fundamentais, tanto individuais quanto transindividuais na atual sociedade de risco,

\footnotetext{
${ }^{5} \mathrm{CF} / 88$ : Art. 205. A educação, direito de todos e dever do Estado e da família, será promovida com a colaboração da sociedade, visando ao pleno desenvolvimento da pessoa, seu preparo para o exercício da cidadania e sua qualificação para o trabalho.

${ }^{6}$ Bulos defende os direitos fundamentais de sexta geração, vê-se que estes correspondem à democracia, à liberdade de informação, ao direito de informação e ao pluralismo político.
} 
neoliberal, pós-moderna, massificada e globalizada. Diante deste contexto, destaca-se a importância de se proceder ao presente estudo sobre os papéis de cada um destes atores, com base numa análise econômica do Direito.

O Estado, a empresa e a cidadania precisam se reinventar, pois as transformações que ocorrem numa velocidade acelerada assim exigem. Atuações do Estado, da empresa e da cidadania praticadas em determinada localidade são divulgadas imediatamente e podem alcançar amplitude global em segundos, além de provocar efeitos que podem extrapolar os limites de uma determinada localidade e até mesmo de determinado Estado, afetando a comunidade internacional.

O Estado Neoliberal e pós-moderno tem se afastado de grande quantidade de serviços sociais, previdenciários, assistenciais e prestacionais que tinha incorporado sob a égide do welfare state, adotando uma postura mais reguladora e fiscalizadora, na tentativa de se tornar mais eficiente e célere no atendimento das demandas sociais e na efetivação de políticas públicas. Esta postura propicia otimizar suas ações no intuito de realocar recursos e conseguir um maior equilíbrio nas finanças públicas. Neste intento, a reforma administrativa ocorrida no Brasil com a EC 19/98 alterou a redação do art. 37 da CF/88, para guindar ao status constitucional o princípio da eficiência.

A empresa, desde a teoria neoclássica, defendida por Coase, busca otimização dos custos de transação, com o intuito de maximizar os lucros sem, contudo, olvidar sua função social consubstanciada nas relações de mercado, trabalhistas, sociais e até mesmo na preservação do meio ambiente. O empresário deve levar em conta todos os custos de transação quando da decisão de empreender, na atual sociedade massificada e de risco. Estado, cidadania e sociedade organizada adotam uma postura exigente com respeito ao papel da empresa.

A empresa deve preocupar-se ainda com o cumprimento dos contratos assumidos com fornecedores e nas relações de consumo, baseados na boa-fé e na honestidade, pois tais condutas refletem na imagem dela, além de serem fatores de equilíbrio no mercado.

Outro grave problema que deve ser combatido pela empresa, com auxílio do Estado e da cidadania, é a redução da corrupção, pois esta prática é capaz de prejudicar o desenvolvimento em todas as suas vertentes, frustrando sobremaneira o sucesso de políticas públicas e estimulando a prática de atividades ilícitas. 
A cidadania, por sua vez, desempenha um papel importantíssimo na atual sociedade massificada, no que tange aos direitos fundamentais, sobretudo os direitos difusos, coletivos e individuais homogêneos.

A atual Carta Política posiciona a cidadania no centro do poder, quando menciona, no parágrafo único do artigo primeiro, que todo poder emana do povo. Portanto, não há como negar a imprescindibilidade do titular do poder (o povo) na construção de uma ordem social e econômica baseada nos princípios reitores dos direitos humanos e econômicos.

Uma sociedade civil organizada e, como menciona o preâmbulo da Constituição Federal, livre, justa e solidária, é fator preponderante para o desenvolvimento de um Estado Democrático de Direito, promovendo o desenvolvimento social, econômico, cultural, bem como a preservação do meio ambiente para as presentes e futuras gerações.

Desenvolvimento social pressupõe liberdades, dentre elas se podem citar liberdade de pensamento, de associação, de expressão, de locomoção e de participação política. Como bem salienta Amartya Sen, tais liberdades devem estar associadas a oportunidades.

O Brasil, por ser uma democracia relativamente recente, ainda enfrenta certa apatia na participação da arena de debates das políticas públicas, apesar de já ter conquistado algum avanço. Mencionada apatia advém da herança de décadas de regime ditatorial e autoritário, em que o silêncio imperava.

A ampliação da participação da cidadania nas políticas públicas e na defesa e efetivação dos direitos fundamentais individuais e coletivos demanda uma educação para o exercício da cidadania. Uma educação para a cidadania, aliada ao acesso à informação, é capaz de inserir a cidadania na arena de debates de políticas públicas sociais, econômicas e culturais.

Dessa maneira, os três atores no processo de proteção e efetivação dos direitos fundamentais individuais e coletivos na atual sociedade de risco terão que se reinventar e readaptar às intensas transformações pelas quais a sociedade contemporânea vem experimentando. Somente por meio da atuação responsável, consciente e racional do Estado, da empresa e da cidadania se poderá equacionar a questão da lucratividade das empresas sem desprezar sua função social e o desenvolvimento econômico, social e cultural da sociedade na qual está inserida.

\section{REFERÊNCIAS BIBLIOGRÁFICAS:}


ALMEIDA, Gregório Assagra de. Direito material coletivo: superação da summa divisio direito público e direito privado por uma nova summa divisio constitucionalizada. Belo Horizonte: Del Rey, 2008.

ALMEIDA, Maria Christina de. A Função Social da Empresa na Sociedade Contemporânea: Perspectivas e Prospectivas. Unimar, Marília, v. 3, p. 141 - 151, 2003.

ANDRADE, Sinara Lacerda. Publicidade lesiva e responsabilidade civil objetiva: proteção do consumidor na era da modernidade líquida. São Paulo: Editora Lualri, 2017.

BOBBIO, Norberto. A Era dos Direito. Rio de Janeiro: Campus, 1992. BONAVIDES, Paulo. Curso de Direito Constitucional. 24a edição. São Paulo: Malheiros, 2009.

BRASIL. Código de processo civil. Lei no 13.105, de 16 de março de 2015. Acessível em http://www.planalto.gov.br/ccivil_03/_ato2015-2018/2015/lei/113105.htm.

BRASIL. Constituição (1988). Constituição da República Federativa do Brasil. Brasília, DF: Senado Federal: Centro Gráfico, 1988.

BULOS, Uadi Lammêgo. Curso de direito constitucional. $8^{a}$ ed. São Paulo: Saraiva, 2014.

COASE, Ronald H. O problema do custo social. Journal of Law and economics, 1960. Traduzido por Francisco Kummel F. Alves e Renato Vieira Caovilla; coordenado pelo Prof. Dr. Luciano Bennetti Timm; revisão técnica de Antônio José Maristrello Porto e Marcelo Lennertz.

DE CICCO, Cáudio; GONZAGA, Álvaro de Azevedo. Teoria geral do Estado e ciência política. $4^{\mathrm{a}}$ edição. São Paulo: Editora Revista dos Tribunais, 2012.

DOWBOR, Ladislau. Informação para a cidadania e o desenvolvimento sustentável. 2004. Disponível em: < http:// dowbor.org/04infocid.doc>. Acesso em: 06 abr. 2018.

FACHIN, Luiz Edson. Teoria Crítica do Direito Civil. À luz do novo Código Civil Brasileiro. $2^{\text {a }}$ Edição. Rio de Janeiro: Editora Renovar, 2003.

FERREIRA, Jussara Suzi Assis Borges Nasser; ALMEIDA, Maria Christina de. A teoria contratual e as relações de consumo na perspectiva civil-constitucional. In: Argumentum Revista de Direito - Universidade de Marília - Volume 3 - Marília: UNIMAR, 2003. Disponível em: unimar.br/biblioteca/publicações/direito/Direito_vol_03.pdf

LIMA, Nelson Paulo. Como não privatizar: uma proposta para o Brasil. Brasília: Valci, 1999. MAKAAY, Ejan; ROUSSEAU, Stéphane. Análise econômica do direito. Tradução Rachel Sztajn. 2a edição. São Paulo: Atlas, 2015. 
OLIVEIRA, Ocimar Barros de. Processo administrativo e democracia participativa. Participação do cidadão no processo administrativo: garantia fundamental do Estado Democrático de Direito. São Paulo: Editora J.H. Mizuno, 2014.

REALE, Miguel. Visão geral do Projeto de Código Civil. Revista dos Tribunais, n. 752, ano 87, jun. 1998, pp. 22-30.

RIBEIRO, Marcia Carla Pereira; GALESKI JUNIOR, Irineu. Teoria geral dos contratos: contratos empresariais e análise econômica. $2^{a}$ edição rev., atual. e ampl. São Paulo: Editora Revista dos Tribunais, 2015.

SEN, Amartya. Desenvolvimento como liberdade; Tradução Laura Teixeira Motta. São Paulo: Companhia das Letras, 2010.

STRECK, Lenio Luiz; RAATZ, Igor. A teoria dos precedentes à brasileira, entre o solipsismo judicial e o positivismo jurisprudencialista ou "de como o mundo (não) é um brechó". Revista de Processo - RePro 262, p. 379/ 411.

TÁCITO, Caio. Do Estado liberal ao Estado de bem-estar-social. In: Temas de direito público: estudos e pareceres. Rio de Janeiro: Renovar, 1997. 